\title{
Balkan Savașları ve Mevlana Zafer Ali Han
}

\section{The Balkan Wars and Maulana Zafar Ali Khan}

\author{
Hatice GÖRGÜN ${ }^{1}$
}

'Sorumlu yazar/Corresponding author: Hatice GÖRGÜN (Arş. Gör.),

Istanbul Üniversitesi, Edebiyat Fakültesi, Doğu Dilleri ve Edebiyatları Bölümü, Urdu Dili ve Edebiyatı Anabilim Dalı, İstanbul, Türkiye E-posta: hatice_gorgun_1@hotmail.com ORCID: 0000-0003-2347-1959

Başvuru/Submitted: 11.11 .2019

Revizyon Talebi/Revision Requested:

14.11.2019

Son Revizyon/Last Revision Received:

10.12.2019

Kabul/Accepted: 10.12.2019

Atıf/Citation: Gorgun, Hatice. "Balkan Savaşları ve Mevlana Zafer Ali Han." Şarkiyat Mecmuası Journal of Oriental Studies 35 (2019), 1-10. https://doi.org/10.26650/jos.2019.007

\section{öz}

1812-1813 yılları arasında patlak veren Balkan Savaşları sırasında bağımsız kalan son Müslüman devlet olan Osmanlı Devleti'ne karşı Hindistan Müslümanları bağlılık hissetmekteydi. Bu bağlamda onların zor günlerinde hem maddi hem de manevi ellerinden gelen her türlü desteği vermeye gayret göstermişlerdi. Savaş sırasında ve sonrasında basın yayın organları yoluyla Mevlana Zafer Ali Han gibi önemli şahsiyetler kamuoyu oluşturmuşlardı. Biz de bu makalemizde Balkan Savaşları sırasında Mevlana Zafer Ali Han'ın çalışmalarından ve şiirlerinden bahsedeceğiz.

Anahtar kelimeler: Balkan Savaşları, Osmanlı Devleti, Mevlana Zafer Ali Han, Zemindâr

\section{ABSTRACT}

During the Balkan Wars that erupted between 1812 and 1813, Indian Muslims felt loyalty towards the Ottoman Empire, which was the last Muslim state to remain independent. India endeavored to provide all kinds of support, both financial and moral, during these difficult days for the Ottoman Empire. During and after the war, important figures such as Maulana Zafar Ali Khan shaped public opinion through the media. In this article, we will talk about the works and poems of Maulana Zafar Ali Khan during the Balkan Wars.

Keywords: Balkan Wars, Ottoman Empire, Maulana Zafar Ali Khan, Zameendar 


\section{EXTENDED ABSTRACT}

Between 8 October 1912 and 29 September 1913, two great wars occured between the Ottoman Empire and the four Balkan states, and these constituted one of the greatest disasters in Turkish history. With the idea of nationalism becoming more prevalent in the Balkans, the change in population rate between Muslims and Christians became a big issue and revolts started to occur. The Serbs and Greeks had the support of great colonial states such as England, France and Russia. Defeat in the Tripoli War before the Balkan Wars caused great disappointment for the Ottoman Empire and the Young Turks. The efforts of the Committee of Union and Progress regarding rapprochement with Germany were also destroying all credibility. The Ottoman Empire, which was on the verge of a major political crisis, now faced the Balkan threat. At this time of social, political, economic and military problems in the Ottoman Empire, Montenegro declared war on 8 October 1912, and thus the first phase of the Balkan Wars began. The war against the Ottoman Empire ended in complete destruction for the Turks. For the Muslim societies that had lost their independence, this attack by the Balkan states against the Ottoman Empire was seen as a "Crusader" attack. Thus, the material and moral support provided to the Ottoman Empire by the Indian subcontinent, which was a colony of England, one of the most powerful Western countries, had great importance during the Balkan wars. Maulana Zafar Ali Khan played an active role in these activities. By means of poems and writings in a newspaper named Zameendar, which he owned, he created great public opinion in the subcontinent. 


\section{Giriş}

Türk tarihinin en büyük felaketleri arasında yer alan Balkan Savaşları, 8 Ekim 1912 ile 29 Eylül 1913 yılları arasında Osmanlı Devleti ile dört Balkan devleti olan Yunanistan, Bulgaristan, Sırbistan ve Karadağ arasında yaşanan birbiri ardına yapılan iki büyük savaşı içermektedir. ${ }^{1}$

Balkan Savaşları'nın oluşumuna zemin hazırlayan tarihi sürece baktığımızda 1804 yılında Osmanlı'ya karşı ilk ayaklanma çıkaranların Sırplar olduğunu görmekteyiz. Fransız İhtilali’nin neden olduğu milliyetçilik hareketi ile Sırplar ayaklanmaya başlamışlardı. 1809 yılında ise Osmanlı-Rus Savaşı sonrasında imzalanan Bükreş Antlaşması ile de geniş imtiyazlara ve iç işlerinde serbestliğe sahip olmuşlardı. ${ }^{2} 1839$ yılındaki Tanzimat Fermanı ve 1856 yılındaki Islahat Fermanı ile Hıristiyan tebaaya tanınan imtiyazlar sayesinde batı himayesi altında Osmanlı Devleti'ne karşı kuvvetlenmelerine yol açmıştı. Ekonomik, sosyal ve kültürel güce sahip olan tüccar ve aydın sınıfları da bu milliyetçi akımlara öncülük etmişlerdi. Milliyetçilik düşüncesinin Balkanlarda artmasıyla Müslüman ve Hıristiyan arasındaki nüfus oranı değişimi büyük bir mesele haline gelmişti. Sırpların Osmanlı idaresine karşı 1804 yılında ayaklanmasından sonra, 1821 yılında Osmanlı Devleti'ne karşı Yunan ayaklanması patlak vermiş; İngiltere, Fransa ve Rusya gibi büyük Avrupalı devletlerin desteğini alan Yunanistan 1829 yılındaki Edirne Antlaşması ile bağımsızlığını kazanmıştı. ${ }^{3}$ Böylece Sırp ve Yunanlıların ardından Osmanlı Devleti'nin Balkanlar'daki hâkimiyeti iyice zayıflamaya başlamıştı. 1877-78 Osmanlı-Rus Savaşı'ndan sonra Makedonya ve Trakya hariç Balkanlar'ın büyük bir kısmı Osmanlı idaresinden çıkmış, Ayastefanos ve Berlin Antlaşmaları ile de bağımsızlıklarını ilan etmişlerdi. Böylece Balkanlardaki üstünlük artık Ruslara geçmişti. Berlin Antlaşması ile Karadağ da bağımsızlığını ilan etmiş, Bulgar Prensliği kurulmuştu. Bulgar Prensliği, 1908 yılında II Meşrutiyetin ilanı ile Osmanlı Devleti'nde çıkan karışıklıklardan istifade ederek bağımsızlığını ilan etmişti. Bosna Hersek ise Avusturya tarafından işgal edilmiş, Eflak ve Boğdan Beylikleri de Berlin Antlaşması ile Bağımsız Romanya Krallığı haline gelmişti.

1 Hamiyet Sezer Feyzioğlu, "Hatıraların Işı̆̆ında Balkan Savaşları", DTCF Dergisi, Ankara 2016, Sa. 56/2, s. 200.

2 Arzu Çiftsüren, “93 Harbi'nden Sonra Hindistan-Pakistan Alt-Kıtası'nda Urduca ve Farsça Şiirde Türkiye ve Türkler", Basılmamıș Doktora Tezi, İstanbul 2013, s. 148.

3 Salim Aydın, “Osmanlı Basınında Balkan Savaşları (1912-1913)”, Basılmamış Doktora Tezi, İstanbul 2012, s. 3-4. 
Mora ve Vardar nehirleri üzerinde bulunan Orta Avrupa'yı Akdeniz’e bağlayan diğer bir Balkan ülkesi olan Makedonya, Balkanların en verimli topraklarına sahip olması ve Türk, Bulgar, Yunan, Sırp ve Arnavut gibi farklı milletleri bir arada barındıran bir yer olması nedeniyle diğer Balkan ülkeleri tarafından ele geçirilmek istenmiştir. ${ }^{4}$ Sömürgeci büyük devletlerin çıkar hesapları da işin içine girince savaş kaçınılmaz olmuştu.

Savaşın çıkmasında Balkanlar'ı paylaşma konusunda Rusya ile Avusturya arasındaki rekabet ve Rusya'nın takip etmiş olduğu Panslavizm siyaseti büyük önem teşkil etmekteydi. Rusya, Makedonya'nın taksimi konusunda fikrini Balkan Devletleri ile paylaşmış, kışkırtmaları sonucunda 13 Mart 1912 yılında Bulgaristan-Yunanistan, Ağustos 1912'de Karadağ-Bulgaristan ve 6 Ekim 1912 yılında da Karadağ-Sırbistan arasında ittifak anlaşmaları yapılmış böylece milliyetçilik düşüncesiyle çözülmelere uğrayarak bağımsızlıklarını elde eden Balkan Devletleri arasında Balkan İttifakı meydana gelmişti. ${ }^{5}$

Balkan Savaşları öncesinde Trablusgarp Savaşı'nın yenilgi ile sonuçlanması Osman11 Devleti ile Jön Türkler açısından büyük bir hayal kırıklığına sebep olmuştu. İttihâd ve Terakki'nin Almanya ile yakınlaşma çabaları da bütün itibarını yok etmekteydi. Çok büyük bir siyasi bunalımın eşiğinde duran Osmanlı Devleti şimdi de Balkan tehdidi ile yüz yüze gelmişti. Ülkenin içinde bulunduğu karmaşa ortamından yararlanma arzusunda olan Balkan Devletleri, Bâbıâli’ye ültimatom vererek Osmanlı ordularının geri çekilmesini, Balkan eyaletlerinin muhtar olmasını ve Hristiyanlar gözetiminde yeni reformlar yapılması gibi Osmanlı Devleti açısından kabul edilmesi mümkün olmayan isteklerde bulunmuşlard1. Hâl böyle olunca sosyal, siyasal, ekonomik ve askerî açıdan birçok s1kıntı içerisindeyken 8 Ekim 1912 yılında Karadağ’’n Osmanlı Devleti’ne savaş ilan etmesi ile Balkan Savaşlarının ilk safhası başlamış oldu. ${ }^{6}$

Savaşın Osmanlı Devleti aleyhine sonuçlanması Türkler için her yönden tam bir yıkımı ifade etmekteydi. Bağımsızlıklarını kaybetmiş Müslüman toplumlar açısından Balkan devletlerinin Osmanlı'ya karşı yapmış olduğu bu saldırı bir "Haçlı" saldırısı olarak görülmekteydi. Böylece Müslüman dayanışmasını esas alan Pan-İslâmizm hareketi güç kazanmış, Batılı devletlere karşı tek yürek olunmuştu. Bu anlamda en güçlü Batılı ülke-

4 Arzu Çiftsüren, a.g.t., s. 149.

5 Zekai Kardaş, “Ebû'l Kelâm Âzâd ve El-Hilâl Gazetesi Çerçevesinde Türkiye ve Türkler”, Basılmamış Doktora Tezi, İstanbul 2011, s. 93.

6 Azmi Özcan, Pan-İslâmizm Osmanlı Devleti Hindistan Müslümanları ve İngiltere (1877-1924), Türkiye Diyanet Vakfi Yayınları, Ankara 1997, s. 189. 
lerden olan İngiltere'nin sömürgesi konumundaki Hint alt kıtasında, Balkan Savaşları süresince Osmanlı’ya karşı yapılan maddi ve manevi her türlü destek faaliyetleri büyük önem taşımaktadır. ${ }^{7}$

Aralarında ayrılıklar olan Diyobendî, Nedvetü’l Ulemâ, Şiî, Barelvî ve Frengî Mahal gibi ulemâ cemiyetleri bile bu dönemde birlik olmuşlar, hatta Osmanlı Devleti'ni desteklemenin farz olduğuna dair fetvalar yayınlamışlardı. ${ }^{8}$ Savaş sonunda yapılan antlaşmalar ile Osmanlı Devleti'nin elinden çıkan topraklarda yaşayan Türkler, mevcut Osmanlı topraklarına göç ederken sağlık sorunları yaşanmıştı. Bu sorunları gidermek adına Hindistan'dan bir tıbbî heyet gelmişti. ${ }^{9}$ Ayrıca Balkanlardaki çarpışmalardan kaçarak Osmanlı'ya sığııan Müslüman muhacirlerin iskân sorununu çözmek amaciyla Osmanlı Devleti tarafından uygun bir arazi temin edilmesi halinde masrafları Hint Müslümanları tarafından karşılanacak yerleşim bölgeleri kurulmasını ön gören ${ }^{10}$; "Zemindâr" gazetesi editörü Zafer Ali Han ve Muhammed Ali’nin sunduğu öneriler ile kurulan “Rumeli Muhacirlerine Yardım Cemiyeti” için çalışmalarda bulunulmuştu. Muhacirlerin kalmaları için uygun yerler bulmak adına Dr. Muhtar Ahmed Ensâri ve Zafer Ali Hân Anadolu’yu karış karış dolaşmış ve en son Adana'da karar kılmışlardır. ${ }^{11}$

\section{Mevlana Zafer Ali Han'ın Balkan Savaşları'ndaki Rolü}

Mevlana Zafer Ali Han, 1919 yılından 1931 yılına kadar Hindu-Müslüman birliği için siyasi platformda büyük bir rol üstlenmiş Müslüman liderlerden biri olmasına rağmen tarihçilerin çoğu onun gazeteci, yazar ve şair kimliğine önem vermektedir. ${ }^{12}$

Zafer Ali Han, Pencap bölgesindeki özgürlük hareketinin önde gelen liderlerinden biriydi. Balkan savaşları esnasında Hindistan'da "Zemindâr" isimli bir gazete yayımlanmaya başlamıştı. Bu gazetede bir yandan İngiltere'nin aleyhinde ateşli yazılar yazı-

7 Hasan Taner Kerimoğlu, “Trablusgarp ve Balkan Savaşları’nda Hint Müslümanlarının Osmanlı Devleti’ne Yaptıkları Yardımlar”, Türk Dünyası İncelemeleri Dergisi, Kış 2012, s. 162.

$8 \quad$ Azmi Özcan, a.g.e., s. 190.

9 Zuhal Özaydın, “The Indian Muslims Red Crescent Society's Aid to the Ottoman State During the Balkan War in 1912", Journal of the International Society for the History of Islamic Medicine (ISHIM), 2 (4): 12-18, 2003, s. 13.

10 Hasan Taner Kerimoğlu, a.g.m., s. 178.

11 Zuhal Özaydın, a.g.m., s. 13.

12 Zahida Suleman, "Maulana Zafar Ali Khan and Hindu Muslim Unity", Proceedings of the Indian History Congress, Sa. 75, s. 1341 . 
lırken, bir yandan da Osmanlı Hilâl-i Ahmer'i için para toplanmaktayd1. ${ }^{13}$ Aslında 1903 yılının Haziran ayından itibaren haftalık olarak okuyucuyla buluşan bu gazeteyi ilk kez Zafer Ali Han'ın babası olan Mevlana Siraceddin Ahmed çıkarmaya başlamıştı. Gazetenin çıkış amacı köylüler çiftçiler ve toprak sahipleri hakkında haber yayınlamak idi. Ancak babası ölünce Zafer Ali Han, bu dönemde yaklaşık 2000 tiraja sahip olan bu gazetenin yöneticiliğini üstlenmiş ve gazetenin içeriğinde çeşitli değişiklikler yaparak Hint Müslümanları hakkında haberler yayınlamaya başlamıştı. Bu değişikliğin ardından Zemindâr'a olan ilgi daha da artmış ve günlük olarak çıkarılmaya başlanmıştı. Haber kaynaklarını genişletebilmek için "Reuters" ve "Associated Press of India" gibi yabancı haber ajanslarına abone olmuş, böylece herkesten önce haber temin edebilme şansını yakalamıştı. Zafer Ali Han, Lahor'da yayımlanan dini ve siyasi konuların yanında Urdu Edebiyatı ile ilgili çeşitli çalışmaların da bulunduğu "Mahzen" adlı derginin yayın kurulunda da görev almıştı. ${ }^{14}$

Trablusgarp Savaşı henüz sürerken, Balkan Devletleri isyan bayrağı çekince Osman11 Devleti mecburen savaşı bitirmek zorunda kalmıştı. Ardından da Balkan Savaşları başlamıştı. Tarihi sürece baktığımızda İngiltere her zaman Rusya'yı tehdit olarak görmüş, bunun için de Osmanlı ile aynı safta yer almıştı. Ancak Trablusgarp ve Balkan Savaşları döneminde artık durumun aynı olmadığını İngiltere'nin Osmanlı’ya karşı muhalif güçleri desteklediğini görüyoruz. Nitekim Mevlana Zafer Ali Han'ın bu durumu eleştirir yönde birçok şiiri bulunmaktadır. ${ }^{15}$

Bu dönemde Zafer Ali Han, Türklere yardım etmek amacıyla bir kampanya başlatmış ve bu kampanyada yaklaşık altı milyona yakın miktarda para toplanarak Osmanlı Devleti’ne gönderilmişti. Ayrıca Balkan Savaşları'nda yaşanan çeşitli olayların anlatıldığı birçok şiir de kendisi tarafından kaleme alınmıştı. Zafer Ali Han, hem nazım hem de nesir türünde yazdığı eserleri vasıtasıyla Müslümanlara hilafetin sona ermesinin İslâm açısından büyük bir eksiklik doğuracağını ve Müslümanların birlikteliğinin dağılacağını anlatmaya çalışmıştı. Şiirlerinde Türklerin başarılarından ve Müslümanların kahramanlıklarından defalarca bahsederek Hindistanlıların cesaretini arttırmak için büyük bir çaba sarf etmişti. Daha önce de belirttiğimiz gibi Dr. Muhtar Ahmed Ensari’nin ön-

13 Mustafa Keskin, Hindistan Müslümanları’nın Millî Mücadele’de Türkiye’ye Yardımları (1919-1923), Erciyes Üniversitesi Yayınları, No: 21, Kayseri 1991, s. 23.

14 Zekai Kardaş, a.g.t., s. 62-63.

15 Subhan Allah, "Maulana Zafar Ali Khan ki Şairi main Mağribi İst'imar ke Khilaf Mezahmeti Ruye Tahkiyki Makalah”, Basılmamış Doktora Tezi, Peşaver 2015, s. 122-123. 
derliğinde Balkan Savaşlarında yaralanan Türk askerlerine tıbbî yardımda bulunmak amacıyla Türkiye'ye Hindistan Hilâl-i Ahmer cemiyetinden doktor ve hasta bakıcılardan oluşan bir heyet gelmişti. Mevlana Zafer Ali Han, bu ekibe katılmak istemişse de Hükümet'in öğrenmesi halinde kendisinin Bombay’a dahi ulaştırılmayacağını düşünmekteydi. Bu nedenle gizlice Türkiye'ye gidip orada Dr. Ensari ile buluşmuş, yetkililerle bizzat görüşmüştü. Sultan ile görüştüğünde Farsça olarak kendisinin şanına yakışır bir kaside dahi sunmuştu. Üç aylık bir süre sonunda ülkesine geri dönerken Hamidiye Kaptanı Rauf Paşa ile de görüşmüştü. ${ }^{16}$

\section{Mevlana Zafer Ali Han'ın Balkan Savaşları Üzerine Kaleme Aldığı Şiirlerinden Seçmeler}

Tüm bunlar yaşanırken Balkan Savaşları sırasında moral ve motivasyonu düşürmek amacı ile İngiliz haber ajansları özellikle de Reuters'da yalan haberler yayınlanmaktaydı. Bu durum üzerine Zafer Ali Han Zemindâr gazetesinde 20 Kasım 1912 tarihindeki sayısında "Â'yň Bâ'yň Şâ'yň” (Uydurmaca) adlı bir şiir yazmıştı. Bu şiirden birkaç mısrayı aşağıda bulabilirsiniz. ${ }^{17}$

Avrupa zulmüyle dünyada deprem yaratsın

Müslümanlar dualarıyla göğü harekete geçirsin

Reuters ümitsizlerin imanını satın aldı

Biz neden "Lâ taknetu"18 demeyelim?

Bütün herkes sansür kafesinin içinde mahkûm

Gazeteciler savaş haberlerini nasıl, nereden getirsinler.

Bunun üzerine de onlar saçma sapan konuşursa,

Hadi, biz de onları neden eleştirmeyelim?

16 Subhan Allah, a.g.t., s. 124-125, 127, 129.

17 Arzu Çiftsüren, a.g.t., s. 186, 188.

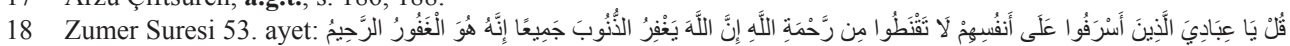
(De ki: Ey kendilerinin aleyhine ileri giden kullarım! Allah'ın rahmetinden ümidinizi kesmeyin. Şüphesiz Allah, bütün günahları affeder. Çünkü o çok bağışlayandır, çok merhamet edendir”. 
Mevlana Zafer Ali Han 1913 yılında İstanbul'da yazdı̆̆g “Sir Edward Grey” isimli şiirinde İngiliz Dışişleri Bakanına hitaben İslâm ülkelerinin içinde bulunduğu Haçlı saldırısını ele almıştı. Bu şiirinde, sırf Müslüman olduğu için Batı tarafından saldırılan İslâm beldelerini sayarken bu durum karşısındaki üzüntü ve hayal kırıklığını şu dizelerle ifade etmiştir: ${ }^{19}$

Balkan Ovasında Avrupa'nın işte bu emri vermesi:

“Bunlar Müslümandır, Müslüman olma suçuyla onları öldürün”.

Filistin tarafından kılıç kokusu geliyor,

Kudüs meydanı kan kan ırmak,

Bağdat ve Suriye Hristiyanlık dinine emanet.

Gerçi bugün dünyanın dört bir tarafında

Senin ümmetin hesapsız sitemlere rehindir;

Ama ben vatan toprağına tapan değilim.

Hiçbir şekilde bu putu (toprak parçasını) yüceltmiyorum.

Müslümanların izzetini korumak için,

Omuzda binlerce başım kesilmeye amade.

Zemindâr gazetesinde bu süreçte Balkan savaşlarıyla ilgili pek çok şiir yayımlanmıştır. Modern Urdu şairleri arasında yer alan Hâşimî Ferîd Abâdî adeta savaş alanına koşulması için insanı harekete geçiren "Balkan Daveti” isimli şiiri de yine Zemindâr gazetesinde yer alan şiirlerdendir: ${ }^{20}$ 
İman davası koyulmuş, ey Mümin kalk yürü

Biraz gayret kalmışsa yürü Balkan yürü

Yeter, ben şimdi artık kendi nefis ülkemin mutlak sultanıyım

Yeter, artık bugünden benim işverenliğim başlar

\section{Sonuç}

Yunanistan, Bulgaristan, Sırbistan ve Karadağ'dan oluşan Balkan Devletleri, Rusya'nın kışkırtmaları sonucunda milliyetçilik duyguları ile bağımsızlıklarını ilan etmeye başlamışlardı. Hindistan Müslümanları da Türk toplumunun karşılaştığı bu hüzün verici durum karşısında bağımsız kalan son Müslüman devletin yanında yer almayı kendilerine vazife bilmişlerdi. $\mathrm{Bu}$ maksatla tanınmış şahsiyetler topluma öncülük etmişlerdi. $\mathrm{Bu}$ isimlerden Mevlana Zafer Ali Han'ın çalışmaları da büyük bir önem arz etmektedir. Biz de bu çalışmamızda kendisi sayesinde Türk toplumunun o sıkıntılı dönemlerinde sağladığı maddi ve manevi desteklerini ele almaya çalıştık. Mevlana Zafer Ali Han, Osmanlı hilafetini kendi canından öte görmekteydi ve bunun içinden elinden gelen ne varsa yapmaya hazırdı.

\footnotetext{
Hakem Değerlendirmesi: Dış bağımsız.

Çıkar Çatışması: Yazar çıkar çatışması bildirmemiştir.

Finansal Destek: Yazar bu çalışma için finansal destek almadığını beyan etmiştir.

Peer-review: Externally peer-reviewed.

Conflict of Interest: The author has no conflict of interest to declare.

Grant Support: The author declared that this study has received no financial support.
}

\section{Kaynakça/References}

Allah, Subhan "Maulana Zafar Ali Khan ki Şairi main Mağribi İst'imar ke Khilaf Mezahmeti Ruye Tahkiyki Makalah”, Basılmamıș Doktora Tezi, Peşaver 2015.

Aydın, Salim “Osmanlı Basınında Balkan Savaşları (1912-1913)”, Basılmamış Doktora Tezi, İstanbul 2012. Çiftsüren, Arzu '93 Harbi’nden Sonra Hindistan-Pakistan Alt-Kıtası'nda Urduca ve Farsça Şiirde Türkiye ve Türkler”, Basılmamış Doktora Tezi, İstanbul 2013.

Feyzioğlu, Hamiyet Sezer “Hatıraların Işı̆̆ında Balkan Savaşları”, DTCF Dergisi, Ankara 2016, Sa. 56/2.

Kardaş, Zekai “Ebû'1 Kelâm Âzâd ve El-Hilâl Gazetesi Çerçevesinde Türkiye ve Türkler”, Basılmamış

Doktora Tezi, İstanbul 2011. 
Kerimoğlu, Hasan Taner “Trablusgarp ve Balkan Savaşları'nda Hint Müslümanlarının Osmanlı Devleti'ne Yaptıkları Yardımlar”, Türk Dünyası İncelemeleri Dergisi, Kış 2012.

Keskin, Mustafa Hindistan Müslümanları'nın Millî Mücadele'de Türkiye'ye Yardımları (1919-1923), Erciyes Üniversitesi Yayınları, No: 21, Kayseri 1991.

Özaydın, Zuhal "The Indian Muslims Red Crescent Society's Aid to the Ottoman State During the Balkan War in 1912", Journal of the International Society for the History of Islamic Medicine (ISHIM), 2(4): 12-18, 2003.

Özcan, Azmi Pan-İslâmizm Osmanlı Devleti Hindistan Müslümanları ve İngiltere (1877-1924), Türkiye Diyanet Vakfi Yayınları, Ankara 1997.

Suleman, Zahida "Maulana Zafar Ali Khan and Hindu Muslim Unity", Proceedings of the Indian History Congress, Sa. 75. 